\title{
Mapping interaction patterns of German IT and engineering services for automotive applications
}

\author{
Julian Schwabe and Markus Hassler \\ Department of Geography, Philipps-Universität Marburg, Marburg, Germany \\ Correspondence: Julian Schwabe (julian.schwabe@geo.uni-marburg.de)
}

Received: 18 July 2019 - Revised: 11 March 2020 - Accepted: 27 April 2020 - Published: 28 May 2020

\begin{abstract}
This study explores how technical services for automotive applications organize their value-added activities. It does so from the background of a market transition towards electric vehicles and vehicle connectivity. Conceptually, the article combines the literature stream of global value chains and global production networks (GVC-GPN) and knowledge-intensive business services (KIBS). This paper puts a specific focus on the temporality of client-vendor relationships and argues that interfirm relationships often last longer than their projectbased mode suggests they would. Despite ongoing fundamental transitions of industry structures towards electric vehicles and vehicle connectivity, the relationships of incumbent OEMs and technical service firms continues to be hierarchical. Analyzing these dynamics on the level of value-added inputs, the concepts of GVC-GPN and KIBS meaningfully complement each other for outlining the mutual dependencies of market dynamics, the characteristics of a service input and the organizational outcome of the client-vendor relationship.
\end{abstract}

\section{Introduction}

The importance of technical services for engineering and ITrelated inputs in the German automotive sector has increased significantly over the past 2 decades and will continue to do so in the foreseeable future (Bratzel et al., 2015:61). Various different trends have contributed to this, including digitization of service creation, intensified competition and costpressures, and globalization of production and supply capacities as well as the transition towards electric mobility and vehicle connectivity (Dicken, 2015:480ff.; Rentmeister, 2007:39). These macrotrends have led not only to the externalization of IT and engineering services for product inputs but also to the creation of entirely new service products such as platforms for fleet management. Such services have been characterized in the literature as knowledge-intensive business services (Miles et al., 1995:28), and their diverse modes of operation along different tiers of automotive value chains shape the organizational and territorial configuration of the sector.

From this background, this article explores how IT and engineering services in automotive applications organize their value creation. Specifically, the article attempts to contribute in three areas. First, the parameters outlined in the literature streams of knowledge-intensive business services (KIBS) and global value chains and global production networks (GVC-GPN) shall be combined, in order to provide a holistic concept for the interdependencies of market dynamics, characteristics of value-added inputs of KIBS and organizational outcomes.

Second, this article puts a focus on the conceptualization of the temporality of interfirm relationships and how this aspect relates to characteristics of specific service inputs. Fuchs and Fromhold-Eisebith pointed out an "increasing volatility and temporality of [...] patterns of external collaboration" in the context of an increasingly fragmented organization of the global economy (Fuchs and Fromhold-Eisebith, 2012:4). KIBS firms especially operate on a project basis (Strambach and Klement, 2010:9), enabling client-vendor relationships to be temporary. The most obvious reason for clients to externalize certain services and enter temporary supplier relationships is infrequency of demand for a specific input (Gereffi et al., 2005:81). As will be shown below, aspects such as established routines and the degree of competition are also important determinants for the longevity of a client-vendor relationship. 
Third, this article aims to explore the implications of ongoing dynamics in production systems for electric vehicles and vehicle connectivity on established and upcoming service sectors. While the electrification of vehicle engines is expected to have profound implications for generic component suppliers in Germany (Schwabe, 2020:160f.), it can also be expected to be relevant to technical service companies, making it worthwhile to revisit patterns of KIBS in the automotive sector in an explorative study.

The empirical material for this study was generated through 14 semistructured interviews with representatives of eight companies. In the following two sections, the theoretical framework for this article and a sectoral context of ongoing dynamics in the automotive sector are outlined. Afterwards, the organizational patterns of the creation of service projects by KIBS firms are introduced and conceptualized. The article closes with a conclusion on the value of combining the literature stream of GVC-GPN with that of KIBS and implications for further research.

\section{Global value chains and knowledge-intensive business services}

The concepts of GVC and GPN have coevolved over the last 2 decades and strongly overlap in terms of their purpose and the variables they apply. Empirical studies (such as Pickles et al., 2006; Agostino et al., 2015; Pavlínek and Ženka, 2016) oftentimes reference literature from both approaches. Hence, they are referred to as one literature stream in this study. Conceptual parameters outlined in GVC-GPN also partly overlap with the variables used to analyze patterns and dynamics of knowledge-intensive business services. It is therefore worthwhile exploring how these frameworks can be combined in order to evaluate the interplay of market dynamics, company strategies (with regards to spatial and/or organizational externalization) and resulting interfirm relationships in the context of creating a service product.

The concept of global value chains has its roots in the recognition of increasingly diversified and fragmented patterns of international and interregional trade (Arndt and Kierzkowski, 2001; Feenstra, 1998; Yeats, 2001) in which different kinds of value chains have emerged. In this sense, value chains in different sectors differ in their level of organizational integration and distribution of bargaining power between lead firms and suppliers. The premise of the GVCGPN framework is the assumption that companies in general seek to organize their intra- and extrafirm relationships in a way that allows them to maximize their ability to capture value while minimizing economic risks (Hassler, 2009:2233; Coe and Yeung, 2015:37, 109f.). The degree to which product inputs can and should be externalized then becomes a central strategic question for businesses. Strategic imperatives and options for firms are determined by competitive pressures of the market environment (Coe and Yeung, 2015:82ff.) and their bargaining position (power) vis-à-vis other firms ${ }^{1}$. As decisive determinants for externalization, Gereffi et al. (2005) pointed out the codifiability of an input (to make it transferable over geographical distance), the complexity of the transaction (which may increase transaction costs in cases of high complexity and thus act as a barrier to externalization) and the capabilities of the supply base to produce the input in question (Gereffi et al., 2005:85, 89f.). These parameters determine flows of knowledge and capital and therefore the quality of interfirm relationships and, in consequence, the distribution of risks and opportunities of value capture among the actors of the value chain.

Over the past 2 decades, a wide range of sectors have been analyzed using parameters outlined in the GVC-GPN discussion, including not only industrial sectors such as automotive (Hassler, 2009; Pavlínek and Ženka, 2016; Pavlínek, 2019; Schwabe, 2020), electronics (Raj-Reichert, 2018), or agriculture (von Oppenkowski et al., 2019) but also service sectors such as logistics (Coe, 2014), tourism (Christian, 2016), or finances (Dörry, 2015). The discussion of services in such contexts has predominantly examined their role as intermediaries in a globalized economy (see also Low, 2013), while the value chains of knowledge-intensive business services in the context of product creation have thus far rarely been an explicit focus in discussions of GVC-GPN. The distinct characteristics of KIBS and their products influence the spatial, organizational and temporal configuration of interfirm relationships. KIBS have been identified as an integral part of the emerging knowledge-based economy as facilitators, carriers and sources of innovation (den Hertog, 2000:508). Knowledge constitutes their predominant production factor and also the product they sell, as they source knowledge inputs, recombine them and deliver them to the client. The clients of KIBS are other businesses; hence KIBS constitute a critical infrastructure providing specialized inputs for client products (e.g., engineering or IT-related tasks) or provide specialized services such as marketing, legal advice or software products (Miles et al., 1995:28; Gallego and Maroto, 2015:646).

Organizational patterns of KIBS are heavily influenced by the type of knowledge they source, create and deliver. Literature on KIBS and innovation systems has in particular made the distinction between implicit knowledge, which is generally based on experience, bound to persons, and difficult to codify or transfer and explicit knowledge, which can be codified and transferred over distance (den Hertog, 2000:509; Fuchs, 2014:7). Cases in which KIBS firms act as co-innovators feature particularly interactive client-vendor relationships and rely on the exchange of implicit knowledge, as the client seeks external expertise to create a novel product solution (Hyypiä and Kautonen, 2005:6ff.). The KIBS firm

\footnotetext{
${ }^{1}$ Power can be understood as the ability to influence decisions of other actors to one's own advantage (Henderson et al., 2002:450) or, in other words, as exclusive access to a resource which is sought after by other actors (Liu and Dicken, 2006:1231).
} 
in such a case supports the client in framing the problem and in codeveloping a customized solution (Martinez-Fernandez and Miles, 2006:5). Services of this kind require face-to-face coordination with the client and entail knowledge on the part of the client about how the KIBS module can be integrated into the overall product. As such, they are difficult to offshore and transport over distance (Fuchs, 2014:7).

In this sense (similar to the parameter of codifiability outlined by Gereffi et al., 2005), the possibility of spatial relocation of a service input depends on the degree of its reliance on implicit versus explicit knowledge. The resulting patterns of value creation have commonly been expressed in the types of proximity which are particularly relevant to the creation and delivery of a specific input: From the spatial dimension, this means that, with regards to KIBS, temporary spatial proximity in the form of meetings or workshops is a common type of interaction with the client (this is part of what Torre and Rallet referred to as an expression of "organized proximity"). Virtual proximity, which enables the transfer of codified knowledge over distance via communication technologies, has significantly enabled the spatial decoupling of service delivery for inputs which did not rely substantially on implicit knowledge (Torre and Rallet, 2005:53f.).

A conceptual distinction between spatial and organizational externalization of value-added inputs has not been thoroughly followed through in the GVC-GPN literature, which is also due to the fact that both dimensions are not mutually exclusive (see also Mudambi, 2008:701). The four possibilities resulting from the combination of spatial and organizational externalization (or, in other words, offshoring and outsourcing) represent varying degrees of control and geographical dispersion as one firm seeks to exploit the benefits of external firms and/or locations. Offshoring activities commonly take place as the result of cost pressures as companies externalize standardized, relatively low-value inputs to low-cost locations (Gereffi et al., 2005:97; Gereffi, 2013:19), while seeking external capabilities for basic research and product-specific innovation (Schamp, 2014:31ff.).

The conceptual parameters outlined above are summarized in Fig. 1, which constitutes the framework within which service projects are analyzed on the level of a value-added input. This concept attempts to take into account the situational context (external dynamics) in which the service project in question is embedded and the characteristics of the valueadded input in demand as well as the capabilities of the supply base. These aspects determine the strategic options and imperatives of a client firm with regards to externalization and durability of the client-vendor relationship. It is in particular the characteristics of the value-added input in which categories specific to KIBS are relevant. The degree to which an input can be spatially externalized depends significantly on the degree to which it relies on the exchange of implicit knowledge. The degree to which a service firm delivers innovation, rather than standardized services, is relevant to the complexity of a transaction and arguably has implications for its competitive position and the durability of client-vendor relationships. Hence the term "complexity of transaction", which Gereffi et al. (2005) described as the "complexity of information and knowledge transfer required to sustain a particular transaction, particularly with respect to product and process specifications" (Gereffi et al., 2005:85), may be understood in the context of KIBS as the degree to which the exchange of implicit knowledge is part of a transaction. These indicators then allow us to characterize the quality of the client-vendor relationships and the resulting distribution of risks and value-capture opportunities between supplier and client.

\section{Services, dynamics and structures in the German automotive sector}

The structure of automotive services in Germany has been shaped by various macrolevel dynamics since the 1990s. These include the transformation of the automotive industry from "national" systems (Schamp, 1995) to a globalized sector with high fragmentation of value-added inputs, increasing demand for product customization, shortening product cycles and dynamic growth of emerging markets (Dicken, 2015:480ff.). Another impactful macrotrend affecting product creation was a comprehensive digitization of engineering services during the 1990s and early 2000s, which further enabled the spatial decoupling and outsourcing of engineering service inputs (Rentmeister, 2007:39). In addition, and more recently, the automotive industry has entered a stage of fundamental restructuring by establishing capacities for the development and production of electric vehicles, the development of new offerings related to vehicle connectivity, and the offering of new service models such as car sharing (Dudenhöffer, 2016:119ff.; PwC, 2019). This current transition accelerates the need for IT-related services and increases dependency of incumbent vehicle assemblers on external capabilities as new technological solutions need to be developed which are outside of the traditional core expertise of OEMs (Dicken, 2015:485f.).

Organizationally, such macrotrends have led to an extensive outsourcing of value-added inputs to specialized and generic suppliers and technical service firms (Bratzel et al., 2015:61f.; Schamp, 2014:34). Spatially, these trends have led to the emergence of specialized regional clusters of the automotive industry (such as in Baden-Württemberg) in which complex ecosystems of technical service firms have emerged in order to fulfill diverse roles for the sector (Rentmeister, 2007:18f.; Strambach and Dieterich, 2011:12). These firms source knowledge from diverse external sources leading to regional and international business linkages and knowledge flows as well as an organizational and spatial fragmentation of value-creating activities of IT and engineering services (Strambach and Dieterich, 2011:4). As an implication of this, the creation of such services has undergone a trend of modu- 


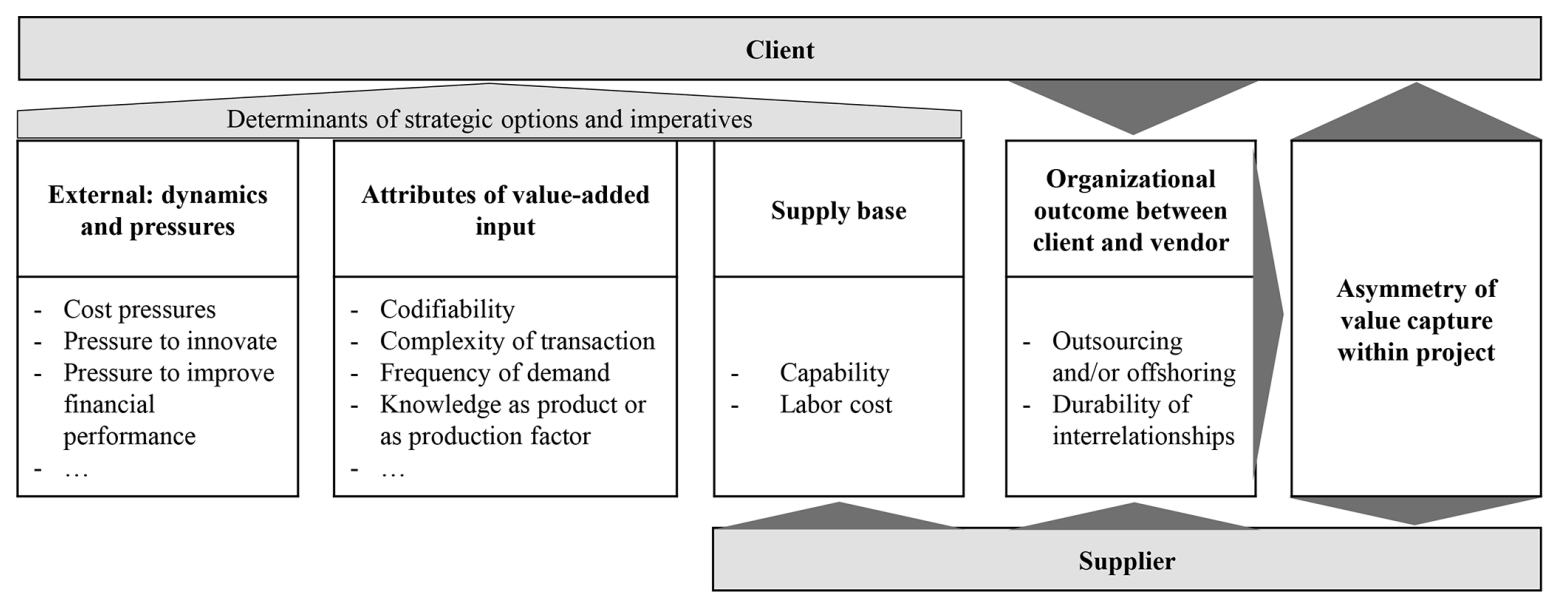

Figure 1. Parameters for the organization of a value-added input (own adaption based on conceptual parameters outlined by Coe and Yeung, 2015:22, and Gereffi et al., 2005:88ff.).

larization, standardization and further externalization of specific value-added inputs to providers further upstream in the value chain (Strambach and Dieterich, 2011:7). Local- and global-level patterns of interaction have emerged as automotive engineering services tend to operate in decentralized networks of multiple locations, some of which are in close spatial proximity to the development centers of large OEM clients. As automotive companies and suppliers have established capacities in emerging markets, the relocation of $\mathrm{R}$ $\& \mathrm{D}$ activities has been typically limited but has occurred as well in pursuit of lower costs and market-specific capabilities (Pavlínek, 2019:5; Fuchs, 2005:141).

While communication technologies increase the flexibility in terms of spatial division of labor, spatial proximity and face-to-face communication between client and service firm has remained important in the delivery of engineering inputs (Rentmeister, 2007:59f.). Company internal division of labor is typically dispersed among various locations of the service firm and resident engineers, who operate on the premises of the client (Rentmeister, 2007:123f., 173). The main modes of operation between engineering companies and automotive clients have been described by Rentmeister (2007) as "extended workbench" and "module development", in which the former represents a clearly defined assignment with relatively low complexity over a limited time. This mode involves limited transfer of product-related knowledge and is characterized by a highly hierarchical relationship between vendor and client. The externalization of the development of modules represents a more complex, less hierarchical mode in which the engineering service undertakes more complex tasks, such as the development of functional units, that involve the (carefully managed) transfer of product-related knowledge. Typically, such development projects are undertaken with multiple engineering firms of which one takes overall project responsibility (Rentmeister, 2007:136ff.).
A permanent challenge from the perspective of automotive manufacturers is the question of how to balance outsourcing of technical services while retaining related technical expertise in-house. This is usually managed by a mixture of formal nondisclosure agreements and informal agreements based on personal trust. The way an OEM client manages the transfer of knowledge with external services is therefore an important indication of how the cooperation is organized. One organizational implication of the competitive pressures in the automotive industry in general is strongly hierarchical relationships between OEMs and tier 1 suppliers on the one hand and dependent suppliers on the other. OEMs generally aim to ensure competition between external suppliers and technical services in order to minimize costs and dependence on external know-how while internalizing critical technical expertise (Rentmeister, 2007:53, 131; Bratzel et al., 2015:64).

\section{Methodology and empirical results}

This study follows a qualitative approach. The empirical material was obtained through 14 semiguided expert interviews with senior-level company representatives in 2018 and 2019. The interview partners were chosen based on their qualification as technical service providers (based on NACE Rev. 2 classification) and their activity in the automotive sector either as providers of IT and engineering services to OEMs or as providers of service solutions for vehicle connectivity. Material obtained during the interviews is complemented by publicly available company information in order to reconstruct a picture that is as realistic and complete as possible. Organizational patterns were outlined within the context of a project that the respective interview partner was familiar with. Table 1 summarizes information about the set of interviewed companies. For the purpose of this study, the semiguided interviews were fundamentally aimed at gaining information about the question of "who contributes which value- 


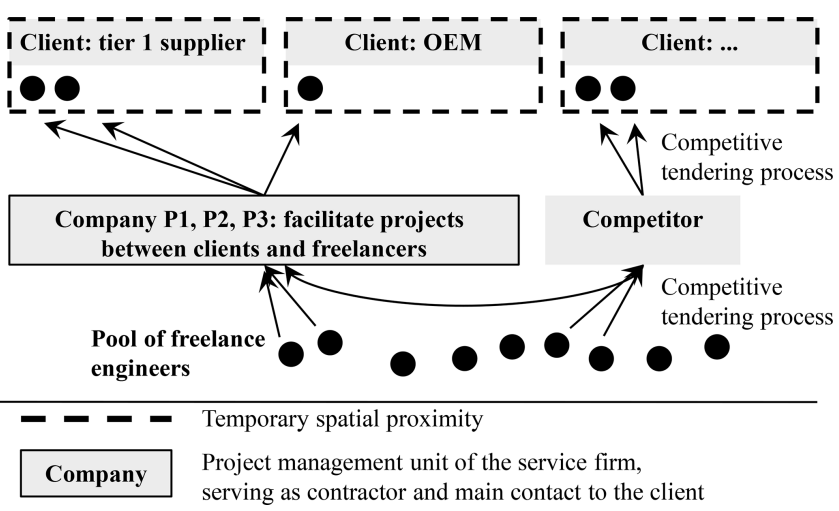

Figure 2. Extended workbench: organizational patterns for generic IT and engineering services (own compilation based on interviews P1, P2, P3).

added input from where and why" and also "how durable are the client relationships". From this empirical basis, the organization of service projects shall be sketched out and analyzed in the following.

\subsection{Extended workbench versus system innovation for OEMs and first-tier suppliers}

Interviewed IT service providers that were providing inputs for onboard vehicle systems showed two distinct organizational patterns as one case entailed standardized and the other innovative activities: First, interview partners P1, P2 and P3 implement a model that can (analogous to generic engineering services described by Rentmeister, 2007) be described as extended workbench visualized in Fig. 2. In this model, the interviewed companies function as platforms, connecting project-related personnel to the client firm (usually an automotive OEM or a tier 1 supplier). On the side of the client and on the side of the freelancers, this is done through competitive project tendering. Only after winning the tendering process does the service firm acquire the personnel required to implement their services. In some cases, after winning the project tender, the service company recruits personnel from a competitor who did not win the tendering. Therefore, while different service companies may win a specific project tender, it is sometimes the same people who actually work on the project after all. An interview partner commented on this as follows:

We have an advantage compared to the competition. If you have a company with 100 employees, then it needs to sell its employees, no matter for what services. I don't sell people, I sell technical solutions. Recently, after winning a project, I hired some colleagues from a competitor of ours who did not win that project so that I could do the project for a different client. (Interviewee P1)

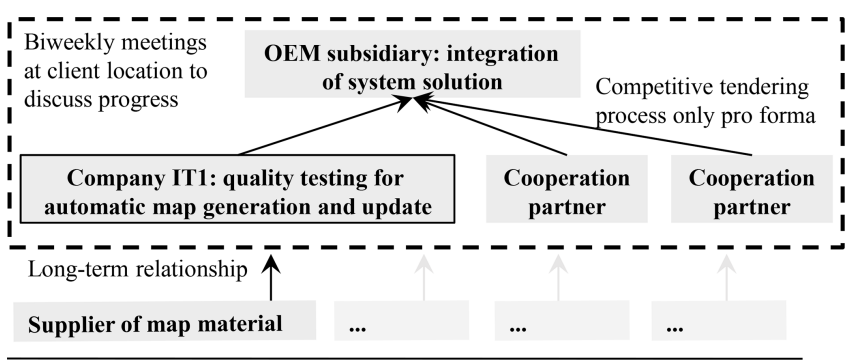

- $\mathbf{c}$ - Temporary spatial proximity

Company

Project management unit of the service firm, serving as contractor and main contact to the client

Figure 3. System innovation: organizational patterns for IT-system solution development for OEM client (own compilation based on interview IT1).

The main purpose of this mode is to temporarily expand capacities of the client while reducing costs and economic risk. Freelancers provide generic, standardized inputs based on explicit client introductions, while the client provides work spaces and interfaces for the integration of their inputs into larger modules. Such a temporary and standardized way of engaging freelance personnel is common for the incremental improvement of existing onboard vehicle systems which can but need not be specific to electric vehicles, such as battery management, lighting, steering, breaks or driving assistance, and involves little innovative activity. As such, the main motivation for the client is to minimize costs in such a process.

In contrast to the strongly hierarchical type of the extended workbench, the project introduced by interviewee IT1 illustrates a more balanced type of interaction within a highly innovative project. The purpose of the project is the creation of an automatic system for updating mapping material on behalf of an OEM subsidiary. The organizational pattern of system innovation is illustrated in Fig. 3.

In this type of interaction, the client (in this case an OEM subsidiary in Germany) coordinates several service companies. Each service company independently delivers a module of a system that is being integrated by the client. Representatives of the main cooperation partners for this project meet in person on a regular basis (usually biweekly) to discuss progress and next steps of the project. In some cases, the cooperation partners of the project are supported by service companies which deliver input for the specific package they are responsible for.

Similar to the organizational pattern described as extended workbench, the service companies for this project are chosen based on competitive tendering (as this is formally required by the client). However, since this project involves a high degree of creativity and innovativeness and therefore relies significantly on the sourcing and exchange of implicit knowledge, personal interaction and the establishment of common routines are important prerequisites for creating the product, 
Table 1. Information about interviewed KIBS firms (source: own compilation based on interviews and publicly available company information).

\begin{tabular}{|c|c|c|c|c|}
\hline ID* & No. of employees & Locations & Clients & Services \\
\hline P1 & $<50$ & $\begin{array}{l}\text { Several project offices in } \\
\text { Germany }\end{array}$ & Tier 1 automotive suppliers & $\begin{array}{l}\text { Software programming (auto- } \\
\text { motive applications, e.g., driver } \\
\text { assistance, entertainment, } \\
\text { battery management) }\end{array}$ \\
\hline $\mathrm{P} 2$ & $<50$ & One location in Germany & $\begin{array}{l}\text { Automotive OEMs, tier } 1 \text { and } \\
\text { tier } 2 \text { suppliers (dominant), } \\
\text { industrial processes and other } \\
\text { sectors }\end{array}$ & $\begin{array}{l}\text { IT (programming, administra- } \\
\text { tion, analysis) and engineering } \\
\text { services }\end{array}$ \\
\hline P3 & 5000 to $<10000$ & $\begin{array}{l}\text { Several project offices in } \\
\text { Germany, Austria and India }\end{array}$ & $\begin{array}{l}\text { Automotive OEMs and tier } 1 \\
\text { suppliers (ca. } 20 \% \text { ), shipbuild- } \\
\text { ing, industrial processes, } \\
\text { aviation }\end{array}$ & $\begin{array}{l}\text { IT and engineering for automo- } \\
\text { tive applications, systems and } \\
\text { production processes }\end{array}$ \\
\hline IT1 & 1000 to $<2000$ & $\begin{array}{l}\text { Multiple locations globally, } \\
\text { incl. USA, Germany, eastern } \\
\text { Europe, China }\end{array}$ & $\begin{array}{l}\text { Automotive OEMs and tier } 1 \\
\text { suppliers, machinery producers }\end{array}$ & $\begin{array}{l}\text { IT and engineering for automo- } \\
\text { tive applications, systems and } \\
\text { production processes }\end{array}$ \\
\hline IT2 & 100 to $<500$ & Several locations in Germany & $\begin{array}{l}\text { Automotive OEMs, suppliers } \\
\text { and fleet operators (ca. } 60 \%) \text {; } \\
\text { also aviation, medical technol- } \\
\text { ogy, insurance etc. }\end{array}$ & $\begin{array}{l}\text { Automatic-fleet-management } \\
\text { package (including hardware, } \\
\text { server space, software), data- } \\
\text { based analysis, sensors, } \\
\text { measuring instruments }\end{array}$ \\
\hline IT3 & 50 to $<100$ & One location in Germany & $\begin{array}{l}\text { Commercial fleet operators and } \\
\text { car dealerships }\end{array}$ & $\begin{array}{l}\text { Automatic-fleet-management } \\
\text { package (including software } \\
\text { and cloud application) }\end{array}$ \\
\hline E1 & 100 to $<500$ & $\begin{array}{l}\text { Multiple locations globally, } \\
\text { including Germany, USA, } \\
\text { eastern Europe }\end{array}$ & $\begin{array}{l}\text { Construction companies for au- } \\
\text { tomotive production (ca. } 75 \% \text { ) }\end{array}$ & $\begin{array}{l}\text { Consulting, planning, training } \\
\text { and construction for process- } \\
\text { related IT and machinery }\end{array}$ \\
\hline E2 & 50 to $<100$ & $\begin{array}{l}\text { Multiple locations globally, } \\
\text { including Germany, eastern } \\
\text { Europe, China }\end{array}$ & $\begin{array}{l}\text { Construction companies for } \\
\text { automotive production } \\
\text { (dominant) }\end{array}$ & $\begin{array}{l}\text { Plant engineering services incl. } \\
\text { software development, automa- } \\
\text { tion, planning, 3D visualization }\end{array}$ \\
\hline
\end{tabular}

$* \mathrm{P}=$ platform, $\mathrm{IT}=\mathrm{IT}$ firm, $\mathrm{E}=$ engineering firm.

making each cooperation partner hard to replace by renewed competitive bidding. Thus, project bids are only undertaken formally, while the same parties remain employed over the duration of all project stages.

\subsection{Plant engineering}

Two plant engineering companies outlined their interaction patterns and branch-specific dynamics (Fig. 4). Both interviewed companies from this sector (E1 and E2) are active in multiple locations worldwide. The spatial setup of those companies is determined by the necessity to be present in the same markets as vehicle OEMs, who constitute the end client in these cases.

The organizational pattern outlined by these interview partners shows an engineering input into production facilities of the OEM client, entailing the design of a production facility for electric vehicles. Service inputs include the design, construction and delivery of specific tools, 3D modeling and the development and installation of automation software. These services are developed in-house and are based on the internal know-how of the engineering service company. Spatial proximity to the client is important, as it helps for project acquisition, inspecting the client's production facilities and delivering the end product. On the side of cooperation partners, some generic project inputs (such as standard design tasks based on a template or detailed instruction) are offshored to low-cost locations, as interview partner E2 described:

The know-how of those firms [at low-cost locations] is such that they are working off tasks. Concepts are being made in Germany, and then cheap resources were sought to implement the construction plan, mostly 2D. (Interviewee E2) 


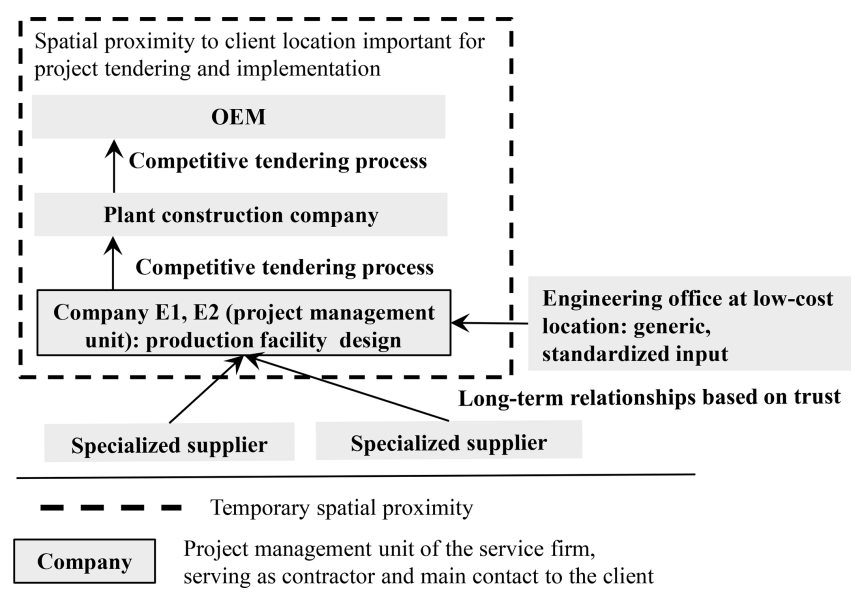

Figure 4. Plant engineering: organizational patterns for IT-system solution development for OEM client (own compilation based on interviews E1 and E2).

Other cooperation partners deliver customized hardware components for tools and machinery. The relationship to these external cooperation partners was described by interview partners as long-term relationships based on trust. The personal connections which characterize such relationships significantly simplify transactions between vendor and service firm, as both sides implicitly know the requirements and conditions of transactions of the other party. Such a (partly) informal, trust-based relation makes it unnecessary to permanently renegotiate terms as would be the case for a competitive project tender.

Both interviewed firms expressed that their respective services branch is currently at a crossroads with regards to automotive production. With the market uptake of electric vehicles, the requirements for production facilities change significantly, as new infrastructure for electric vehicle assembly and battery production features higher automation, lower requirements for space and lower manual-work input. Designing such facilities increases the demand for IT specialists and prompts traditional plant engineering companies to adjust their service portfolio. An interviewed representative from E1 described this as follows:

Electric mobility leads to a need in adapting and building new plants, so this is a potential for us. But more importantly, in the future you need connected production components and less massive machinery. We are fairly good at delivering the whole digital process chain including the development of control systems, their integration and the related software programming. So in the future, OEMs can circumvent classical plant construction firms altogether and directly hire us.

While the services of the interviewed plant engineering companies are diverse, they are generally based on institu-

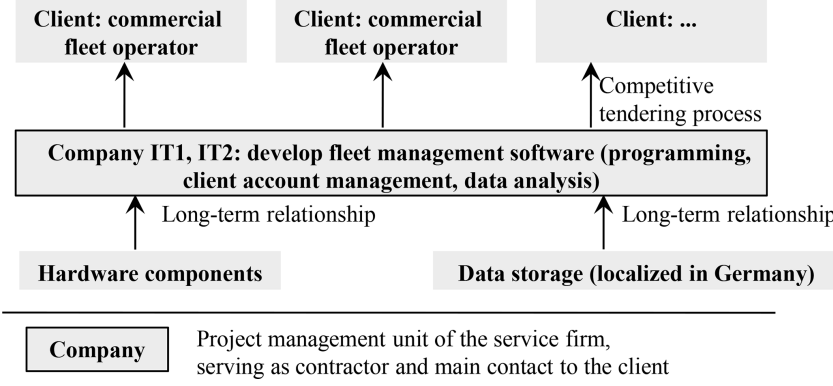

Figure 5. Turnkey solution: organizational patterns for IT-system solutions for commercial end user (own compilation based on interviews IT2, IT3).

tional and external knowledge which they apply and source to create a customized solution for the client. The delivery of their services entails no product-related know-how transfer.

\subsection{Turnkey solutions for commercial end users}

Two of the interviewed IT-service firms were active in delivering management solutions for commercial vehicle fleets which would offer diverse functions such as vehicle tracking, registration and administration of the drivers and analysis of the data produced by the fleet. The projects described by these interviewees feature a different client group and also different product characteristics compared to the ones described above. They resemble a client-vendor relationship of a modular type, wherein the service company delivers a turnkey solution ready to be applied by the user (in this case a commercial vehicle fleet operator). This organizational pattern is outlined in Fig. 5.

The automatic-fleet-management service packages described by companies IT2 and IT3 are not integrated into the vehicle as built-in solutions but consist of a hardware module that can be attached to the vehicle, software apps and the storage space where the data of client accounts are located. The pattern of interaction is simple insofar as the client (a commercial vehicle operator) usually chooses the service company through a competitive bidding process. The interviewed service companies then deliver a fleet management solution that is ready to be used.

In this setting, the system solution (for administering the vehicle fleet and analyzing its use patterns) are developed entirely in-house at the service firm. External vendors deliver hardware components, and also the data storage is managed by an external computer center. An important aspect about the characteristics of this service is that data in this case become a production factor in themselves that can be further monetized in the form of analysis of movement patterns, vehicle maintenance, driver management and other aspects. This provides the opportunity to further engage with existing clients or to offer data-based analysis as an additional consulting service. In contrast to the example of system innova- 
tion, the relatively lower complexity of the fleet management solution (where the software constitutes the core element of the product) allows for the entire development to be undertaken in-house.

\section{Summary and theoretical considerations - the organization of service delivery for automotive applications}

The project examples outlined above display diverse patterns of organization, durability and levels of interorganizational hierarchy. The determinants of the organizational patterns of the service projects described above are summarized in Fig. 6, which builds on the schematic framework introduced in Sect. 2. While the examples of extended workbench, system innovation and turnkey solution displayed relatively consistent patterns within their respective client-vendor relationships and can thus be summarized, the case of plant engineering was more diverse, depending on the particular input. Factors which have been found to be particularly relevant to the externalization and durability of client-vendor relationships are the frequency of demand for a service, the complexity of its transfer to the client and the degree of competition to which a service provider is exposed. The parameters outlined in Fig. 6 overlap with the criteria outlined by Gereffi et al. (2005); however, some adaptions shall be pointed out.

First, the codifiability of an input was a given and is generally a characteristic of technical services (Strambach, 2008:157f.). Thus, it was not a relevant variable per se as it applies at least to a certain degree to all inputs outlined above. Given the codifiability, the main determinants with implications for organizational outcomes of value creation were external pressures, the complexity of transactions (in other words, the degree to which the exchange of implicit knowledge is involved) and the frequency of demand. This is illustrated by the use of freelancers in the extended-workbench pattern, which is a result of organizational externalization due to cost pressures and irregular frequency of demand. However, while this could be a typical case of offshoring to low-cost locations, the relatively unpredictable frequency of demand for the freelancers' services made this option risky. Although competition in this area is strong, client firms preferred to work with partners with a proven track record of performance. The possibility of personal coordination also favors the integration of the value-added inputs of the service firm into the module of the client, making it a more attractive option for the client to provide infrastructure in-house which could be used by freelancers.

Second, one important contribution of the subsequent literature of global production networks is the embeddedness of company strategies into the context of "capitalist dynamics" (Coe and Yeung, 2015:81ff.), which leads to another important point about the scheme provided by Gereffi et al. (2005). A major determinant of the durability of client-vendor rela- tionships as well as of power asymmetries (which are used synonymously with asymmetries of value capture in this article) is the degree of competition to which an actor is exposed or, using the terms of Coe and Yeung (2015), the pressure to improve the cost-capability ratio (Coe and Yeung, 2015:83). The capabilities of the supply base, which Gereffi et al. (2005) pointed out to be a determinant of power asymmetries, need to be seen in this context; it is not the capability per se that determines one's ability to capture value but the degree to which one is replaceable in the market.

The duration of client-vendor relationships does not only depend on the frequency of demand for a specific input. This applies in particular to value-added inputs which involve innovative activity and hence high complexity in their creation and transfer. Such a pattern requires familiarity with the routines and preferences of the other party and, as such, builds to a significant degree on implicit knowledge. In this case, the transaction costs of switching the service provider with any new project through competitive tender exceed the potential benefit of lower prices. The importance of working with persons familiar with the implicit routines and expectations of the client can even go so far that required competitive bids are conducted only pro forma, as the case between service provider IT1 and the OEM client illustrates. Consequently, the mode of a durable long-term relationship that goes beyond one service project was visible among different tiers of the value chain in system innovation, such as the OEM client and interview partner IT1 as well as company IT1 and their specialized vendor of map material. In the context of plant engineering, the relationships between companies E1 and E2 and their specialized service providers could also be characterized in this manner. As a result, despite the high organizational fragmentation of service delivery, the organization of highly customized and complex service products can entail structures which are more durable than their project-based focus may suggest.

The provision of generic IT services as described by interviewees P1, P2 and P3 is in stark contrast to this pattern, as their mode of operation is fundamentally characterized by short-term engagement not only between the client and the service provider but also between the service provider and its own employees, who, in this case, are engaged through short-term contracts for the duration of the project. The example of extended workbench is similar to the pattern of resident engineers described by Rentmeister (2007); however, in this case the employment of engineers by the service firm is nonpermanent. This is illustrative for a pattern which is motivated mainly by cost reductions but, despite its generic nature, does not result in the spatial offshoring of the service to low-cost locations. The creation and delivery of the service does not incorporate the creation and transfer of know-how, but it benefits from face-to-face communication nevertheless because freelance engineers are oftentimes not in charge of delivering a functionally integrated module by themselves but temporarily join a team of engineers on the client side 
Summary of attributes and outcomes of case examples:

\begin{tabular}{|c|c|c|c|c|c|c|c|c|}
\hline \multicolumn{7}{|c|}{ Client } & & \\
\hline \multicolumn{9}{|c|}{ Determinants of strategic options and imperatives } \\
\hline \multirow{2}{*}{$\begin{array}{c}\text { External } \\
\text { dynamics and } \\
\text { pressures }\end{array}$} & \multicolumn{2}{|c|}{ Attributes of value-added input } & \multirow{2}{*}{$\begin{array}{l}\text { Supply base: } \\
\text { intensity of } \\
\text { competition }\end{array}$} & \multicolumn{2}{|c|}{$\begin{array}{l}\text { Organizational outcome between } \\
\text { client and vendor }\end{array}$} & \multirow{2}{*}{$\begin{array}{l}\text { Asymmetry of } \\
\text { value capture } \\
\text { within project }\end{array}$} & \multirow{2}{*}{\multicolumn{2}{|c|}{ Example }} \\
\hline & $\begin{array}{l}\text { Frequency of } \\
\text { demand }\end{array}$ & $\begin{array}{c}\text { Complexity of } \\
\text { transaction }\end{array}$ & & $\begin{array}{c}\text { Mode of } \\
\text { externalization }\end{array}$ & $\begin{array}{l}\text { Durability of client- } \\
\text { vendor relationships }\end{array}$ & & & \\
\hline Cut costs & Irregular & High & High & Outsourcing & Irregular & High & \multicolumn{2}{|l|}{ Extended workbench } \\
\hline Seek expertise & Irregular & High & Low & Outsourcing & Recurring & Low & \multicolumn{2}{|l|}{ System innovation } \\
\hline Seek expertise & Irregular & High & Low & Outsourcing & Recurring & Low & $\begin{array}{l}\text { E1/E2 - specialized } \\
\text { supplier }\end{array}$ & \multirow{3}{*}{$\begin{array}{l}\text { Plant } \\
\text { engineering }\end{array}$} \\
\hline Cut costs & Irregular & Low & High & $\begin{array}{l}\text { Outsourcing, } \\
\text { offshoring }\end{array}$ & Irregular & High & E1/E2 - client & \\
\hline Cut costs & Irregular & Low & High & Offshoring & Irregular & High & $\begin{array}{l}\text { Engineering office } \\
\text { for generic tasks - } \\
\text { E1/E2 }\end{array}$ & \\
\hline \multirow[t]{2}{*}{$\begin{array}{l}\text { Seek solution for } \\
\text { better efficiency }\end{array}$} & Permanent & Low & Low & Outsourcing & Permanent & Low & \multicolumn{2}{|l|}{ Turnkey solution } \\
\hline & & & & & Supplier & & & \\
\hline \multirow{2}{*}{\multicolumn{3}{|c|}{$\begin{array}{l}\text { Recurring combinations of attributes and } \\
\text { outcomes in automotive industry*: }\end{array}$}} & \begin{tabular}{|c|}
$\begin{array}{c}\text { High intensity of } \\
\text { competition }\end{array}$ \\
\end{tabular} & & \multicolumn{2}{|c|}{\begin{tabular}{|l|} 
- Irregular client-vendor relationships \\
- High asymmetry of value capture \\
\end{tabular}} & & \\
\hline & & & \begin{tabular}{|c|}
$\begin{array}{c}\text { Low intensity of } \\
\text { competition }\end{array}$ \\
\end{tabular} & & \multicolumn{2}{|c|}{$\begin{array}{l}\text { - Recurring client-vendor relationships } \\
\text { - Low asymmetry of value capture } \\
\end{array}$} & & \\
\hline \multicolumn{3}{|c|}{$\begin{array}{l}\text { - Pressure to cut costs } \\
\text { - Low complexity of transaction }\end{array}$} & & \multicolumn{2}{|c|}{$\begin{array}{l}\text { Offshore to } \\
\text { low-cost location }\end{array}$} & & & \\
\hline \multicolumn{3}{|c|}{\begin{tabular}{|l} 
- Seeking external capability \\
$\cdot$ High complexity of transaction
\end{tabular}} & & \multicolumn{2}{|c|}{\begin{tabular}{|c|}
$\begin{array}{c}\text { Outsource to capable } \\
\text { supplier in close } \\
\text { spatial proximity }\end{array}$ \\
\end{tabular}} & & & \\
\hline \multicolumn{3}{|c|}{\begin{tabular}{|l} 
Pressure to cut costs \\
$\cdot$ High complexity of transaction
\end{tabular}} & & \multicolumn{2}{|c|}{\begin{tabular}{|c|} 
Outsource to low-cost \\
supplier in close \\
spatial proximity \\
\end{tabular}} & & & \\
\hline
\end{tabular}

Figure 6. Determining parameters and organizational outcomes of service projects analyzed for this study (own adaption). ${ }^{*}$ Excluding the example of turnkey solution.

who jointly develop the functional unit, making the input difficult to offshore.

The purely transactional arrangement outlined in the example of turnkey solution operates outside of the pressures of vehicle OEMs and tier 1 suppliers and has a close resemblance to a value chain which Gereffi et al. (2005) characterized as "modular". The organizational externalization of service inputs is defined by breaking points which divide the product in clearly defined functional units, such as hardware components and data storage. These inputs are defined by the usage (and not the creation and transfer) of knowledge, and their provision is not project-based but permanently ongoing. While those inputs are customized to the requirements of companies IT1 and IT2, they can be integrated with relatively little requirement for face-to-face coordination. Hence, the longevity of client-vendor relationships in this setup is mainly defined by frequency of demand and constitutes a relatively stable setup, as the fleet management solution of IT1 and IT2 as well as their functional subunits requires permanent maintenance and long-term engagement with the client.
The purposeful spatial relocation of service activities within the projects described above was not a major factor and was relevant only to the case of plant engineering in which generic engineering services were sourced at low-cost locations. Also, companies E1 and E2 themselves stated that they increasingly faced competition from low-cost locations for their services. Offshoring is rather common among engineering and software services, who tap into existing knowledge bases in low-cost locations (in this context, commonly capital or metropolitan regions in emerging markets) in order to use these capabilities for generic, noninnovative tasks that support the creation of the service product (Strambach and Klement, 2010:19ff.). The necessary preconditions for the offshoring of such inputs are sufficient capabilities in the supply base (such as the ability to deliver according to specific standards), low transaction costs of transferring the value-added input to the client and infrequency of demand (a service in frequent demand may be offshored in-house under such conditions). The question as to where to source the value-added input then becomes a competition of low labor cost. 
Besides generic engineering for plant construction, all other value-added inputs were produced within Germany, whereas the spatial location of the service companies was determined mainly by close proximity to OEM clients (P1, P2, P3, IT1, E1 and E2) and supply of qualified IT professionals in metropolitan areas (IT2, IT3). Specialized inputs, such as the delivery of map material, data storage or delivery of hardware components, are sensitive in terms of data security or highly customized, and vendors were chosen based on capability and trustworthiness, making the offshoring of such inputs generally difficult. This leads to the observation that (with the exception of the extended-workbench examples) the service projects in question were characterized by a high degree of modularization as functionally integrated units of value-added inputs were delivered by specialized providers, confirming a pattern of low vertical integration and high specialization as observed by Strambach and Klement (2010).

The arrangements outlined above have diverse implications in terms of the distribution of risks and their ability to capture value. As Rentmeister (2007) pointed out, the internalization of product-related know-how is a core competition factor among vehicle OEMs. It is also an important determinant of bargaining positions between clients and vendors along different tiers of the value chain. The more exclusive the access of one party to knowledge which is sought after by the other, the stronger one's bargaining position. The comparison of the examples of extended workbench and systeminnovation offers the most striking contrast in this context.

The innovation of a new system solution as described by company IT1 entails the creation of new know-how which the OEM client aims to internalize. However, unlike the outlined example of the extended workbench, this project enables all involved parties to accumulate technical expertise in their own right, allowing them to exploit it in future projects. While the consortium involved in creating the system innovation is exposed to cost pressures from the OEM client, they are in a stronger position to capture value (in the form of building project-related expertise) and avoid risks (such as ensuring longer-term relationships with the client) compared to the example of extended workbench, where project-related expertise and know-how remain exclusively with the client. The service firm thus cannot accumulate project-specific know-how that would eventually allow them to improve their value proposition. In this case, the role of the service firm is limited to facilitating personnel for generic tasks. Under such conditions, the competition for projects among service firms and freelancers is mainly driven by cost savings, and the externalization of economic risk by engaging freelancers (rather than permanent employees) constitutes an economic advantage.

With regards to the ongoing dynamics in the automotive industry towards electromobility and vehicle connectivity, one interesting observation offered by these case examples is the consistency with how OEM clients attempt to ensure competition among suppliers and services. This also applies to suppliers of generic components, who, in some cases, face existential risk if their products are no longer needed in electric vehicles. Their position as captive suppliers who largely depend on high-volume contracts with OEMs makes it difficult for them to switch to other sectors (Schwabe, 2020:165). In comparison, service companies delivering to vehicle OEMs are in a more favorable position insofar as the demand for the design of new technology solutions is increasing in the context of the ongoing technological paradigm shift. This impression applies quite consistently to all interviewed companies. One interview partner summed up this situation as follows:

We profit strongly from electromobility, because many things are new [...]. But for us [internally] it is no major transition, unlike for companies who build components for combustion engines. (Interviewee P1)

Unlike component suppliers, technical service companies are less capital-intensive and more adaptable to other industries, as their expertise can be adapted across sectors without major capital investments. Hence, most interviewed service companies expressed a positive attitude towards electric mobility, while there are ongoing efforts (especially in plant engineering) to diversify their sectoral focus.

\section{Concluding remarks}

This article explored organizational patterns of creating a service product for automotive applications on a case-study basis. The two literature streams of GVC-GPN and KIBS may meaningfully complement each other insofar as the analytical categories outlined within GVC and GPN can provide a holistic framework of causalities among market dynamics, strategies and outcome in terms of asymmetries of value capture, while the conceptual categories commonly discussed in KIBS literature (such as the dichotomy of implicit versus explicit knowledge) may provide categories for framing the characteristics of service inputs, which in turn lead to organizational, spatial and temporal arrangements which differ from value-added activities of industrial firms.

The service firms for automotive applications outlined in this article broadly reflect the organizationally fragmented and partly modularized manner of IT and engineering services in the automotive industry identified in earlier studies such as Rentmeister (2007) or Strambach and Klement (2010). Amidst organizational decomposition of service inputs in the automotive industry, the durability of client-vendor relationships depends not only on the frequency of demand but also on the level of competition which a service provider is exposed to. In other words, if a service provider features relatively unique capabilities or high familiarity with the routines of the client, it becomes increasingly difficult for the client to source inputs based on open com- 
petition. Even though a fundamental restructuring of production capacities is ongoing with regards to electric vehicles and vehicle connectivity, the organizational patterns of incumbent players appeared to be quite consistent and may be interpreted as an attempt of established OEMs to retain their relatively powerful position vis-à-vis suppliers.

Spatial relocations have played a minor role only, since (unlike in industrial sectors) sufficiently capable suppliers elsewhere and the codifiability of inputs are not necessarily sufficient conditions for offshoring KIBS services. Unlike in capital-intensive industrial firms, the usage, production and transfer of knowledge continues to be a process in which frequent face-to-face communication with client firms can be necessary even for generic, relatively low-value inputs.

Naturally, a qualitative approach as presented in this study comes with limitations: the case studies outlined in this paper are indicative and do not claim to be representative of the diverse ecosystem of technical services in the automotive sector. Further empirical research about interaction patterns of clients, KIBS and vendors in related sectors could help validate and refine the framework presented in this article. Also, conceptually, the oftentimes binary values outlined in Fig. 6 are inevitably a summary and simplification of complex interrelationships which rely on descriptions by interview partners. They are used in this study to compare the value-added inputs of different service companies and could be developed by more precise quantification in future research.

Data availability. The interviews for this study were conducted under the condition of confidentiality. Therefore, the interview scripts cannot be published in order to protect the identity of the interview partners.

Author contributions. JS gathered, prepared and analyzed the empirical material; analyzed the theoretical implications; and drafted and finalized the article. MH analyzed the theoretical implications and provided feedback and recommendations on article drafts.

Competing interests. The authors declare that they have no conflict of interest.

Review statement. This paper was edited by Benedikt Korf and reviewed by two anonymous referees.

\section{References}

Agostino, M., Giunta, A., Nugent, J. B., Scalera, D., and Trivieri, F.: The importance of being a capable supplier: Italian industrial firms in global value chains, Int. Small Bus. J., 33, 708-730, 2015.

Arndt, S. and Kierzkowski, H. (Eds.): Fragmentation: New Production Patterns in the World Economy, Oxford University Press, Oxford, UK, 2001.

Bratzel, S., Retterath, G., and Hauke, N.: Automobilzulieferer in Bewegung - Strategische Herausforderungen für mittelständische Unternehmen in einem turbulenten Umfeld, Hans Böckler Stiftung, Nomos Verlagsgesellschaft, Baden-Baden, Germany, 2015.

Christian, M.: Kenya's tourist industry and global production networks: gender, race and Inequality, Global Netw., 16, 25-44, 2016.

Coe, N. M.: Missing links: logistics, governance and upgrading in a shifting global Economy, Rev. Int. Polit. Econ., 21, 224-256, 2014.

Coe, N. M. and Yeung, H. W.-C.: Global Production Networks theorizing economic development in an interconnected world, Oxford University Press, Oxford, UK, 2015.

den Hertog, P.: Knowledge-intensive Business Services as CoProducers of Innovation, International Journal of Innovation Management, 4, 491-528, 2000.

Dicken, P.: Global Shift, SAGE publications, London, UK, 2015.

Dörry, S.: Strategic nodes in investment fund global production networks: the example of the financial centre Luxembourg, J. Econ. Geogr., 15, 797-814, 2015.

Dudenhöffer, F.: Wer kriegt die Kurve?, Campus Verlag, Frankfurt am Main, Germany, 2016.

Feenstra, R.: Integration of Trade and Disintegration of Production in the Global Economy, J. Econ. Perspect., 12, 31-50, 1998.

Fuchs, M.: Internal Networking in the Globalising Firm: The Case of R\&D Allocation in German Automobile Components Supply Companies, in: Linking Industries Across the World, edited by: Alvstam, C. G. and Schamp, E. W., Ashgate publishing, Frankfurt am Main, Germany, 2005.

Fuchs, M.: Worldwide Knowledge? Global Firms, Local Labour and the Region, Routledge, London, UK, 2014.

Fuchs, M. and Fromhold-Eisebith, M. (Eds.): Changing GlobalLocal Dynamics of Economic Development? Coining the New Conceptual Framework of "Industrial Transition", in: Industrial Transition - New Global-Local Patterns of Production, Work, and Innovation, Routledge, London, UK, 2012.

Gallego, J. and Maroto, A.: The Specialization in KnowledgeIntensive Business Services (KIBS) across Europe: Permanent Co-Localization to Debate, Reg. Stud., 49, 644-664, 2015.

Gereffi, G.: Global value chains in a post-Washington Consensus world. Rev. Int. Polit. Econ., 21, 9-37, 2013.

Gereffi, G., Humphrey J., and Sturgeon, T.: The governance of global value chains, Rev. Int. Polit. Econ., 12, 78-104, 2005.

Hassler, M.: Variations of value creation: automobile manufacturing in Thailand, Environ. Plann. A, 41, 2232-2247, 2009.

Henderson, J., Dicken, P., Hess, M., Coe, N., and Yeung, H. W.-C.: Global production networks and the analysis of economic development, Rev. Int. Polit. Econ., 9, 436-464, 2002. 
Hyypiä, M. and Kautonten, M.: Dimensions of Proximity in Relationships between Knowledge Intensive Business Service Firms and Their Clients, Regional Studies Association International Conference on Regional Growth Agendas, 28-31 May 2005, Aalborg, Denmark, 2005.

Liu, W. and Dicken, P.: Transnational corporations and "obligated embeddedness": foreign direct investment in China's automobile industry, Environ. Plann. A, 38, 1229-1247, 2006.

Low, P.: The role of services in global value chains, in: Global value chains in a changing world, edited by: Elms, D. K. and Low, P., WTO publications, Geneva, Switzerland, 2013.

Martinez-Fernandez, M. C. and Miles, I.: Inside the software firm: co-production of knowledge and KISA in the innovation process, Int. J. Serv. Tech. Manag., 7, 115-125, 2006.

Miles, I., Kastrinos N., Flanagan, K., Bilderbeek, R., Den Hertog, P., Huntink, W., and Bouman, M.: Knowledge-Intensive Business Services - Users, Carriers and Sources of Innovation, European Commission DG13, Luxembourg, 1995.

Mudambi, R.: Location, control and innovation in knowledgeintensive industries, J. Econ. Geogr., 8, 699-725, 2008.

Pavlínek, P.: Restructuring and internationalization of the European automotive industry, J. Econ. Geogr., 20, 509-541, 2019.

Pavlínek, P. and Ženka, J.: Value creation and value capture in the automotive industry: Empirical evidence from Czechia, Environ. Plann. A, 48, 937-959, 2016.

Pickles, J., Smith, A., Bucěk, M., Roukova, P., and Begg, R.: Upgrading, changing competitive pressures, and diverse practices in the East and Central European apparel industry, Environ. Plann. A, 38, 2305-2324, 2006.

PwC: Digital Auto Report, available at: https://www.strategyand. pwc.com/gx/en/insights/2019/digital-auto-report.html (last access: 24 February 2020), 2019.

Raj-Reichert, G.: The Changing Landscape of Contract Manufacturers in the Electronics Industry Global Value Chain, in: Development with Global Value Chains: Upgrading and innovation in Asia, edited by: Nathan, D., Tewari, M., and Sarkar, S., Cambridge University Press, Cambridge, UK, 2018.
Rentmeister, B.: Wissensintensive Dienstleister in der Automobilentwicklung, LIT Verlag, Frankfurt am Main, Germany, 2007.

Schamp, E.: Going European, in: Towards a New Map of Automobile Manufacturing in Europe?, edited by: Hudson, R. and Schamp, E., Springer, Heidelberg, Germany, 1995.

Schamp, E.: The Formation of a New Technological Trajectory of Electric Propulsion in the French Automobile Industry, Deutsches Institut für Entwicklungspolitik, Bonn, Germany, 2014.

Schwabe, J.: Risk and counter-strategies: The impact of electric mobility on German automotive suppliers, Geoforum, 110, 157167, 2020.

Strambach, S.: Knowledge- intensive business services (KIBS) as drivers of multi- level knowledge dynamics, Int. J. Serv. Tech. Manag., 10, 152-174, 2008.

Strambach, S. and Dieterich, I.: The territorial shaping of knowledge dynamics in Baden-Württemberg, Inter-organizational relations in the sectoral knowledge domain of the automotive industry, Working Papers on Innovation and Space, 01.11, available at: https://wpis.files.wordpress.com/2013/08/wp01_11.pdf (last access: 12 February 2020), 2011.

Strambach, S. and Klement, B.: The organisational decomposition of innovation and territorial knowledge dynamics - insights from the German software industry, Working Papers on Innovation and Space, 06.10, available at: https://wpis.files.wordpress.com/ 2013/08/wp06_10.pdf (last access: 12 February 2020), 2010.

Torre, A. and Rallet, A.: Proximity and Localization, Reg. Stud., 39, 47-59, 2005.

von Oppenkowski, M., Hassler, M., and Roesler, T.: Informal markets and global value chains - the disembedding of Romanian dairy smallholders, Eur. Plan. Stud., 27, 995-1012, 2019.

Yeats, A.: Just How Big is Global Production Sharing?, in: Fragmentation: New Production Patterns in the World Economy, edited by: Arndt, S. and Kierzkowski, H., Oxford University Press, Oxford, UK, 108-143, 2001. 